distinguish in from p53 signatures, STIL and invasive carcinoma. All statistical analysis was performed by Stata/IC 13.0 for Windows.

Result(s)* A total of 115 were included. Of them, 50.4\% had BRCA 1 mutation and 49.6\% BRCA 2 mutation. Mean (+/Standard deviation, SD) age at surgery was 49.2 (5.8) years. Of note, $40.9 \%$ underwent surgical menopause. The median Ca-125 value prior to surgery was $29.4 \mathrm{u} / \mathrm{L}$. Adnexal findings in presurgery ultrasound were normal $(104,90.4 \%)$ or benign cyst $(11,17.4 \%)$. Also, endometrial polyps were found in 3.5\% (3) of patients. Pathologic exam showed STIC in $5(4.5 \%)$ patients and invasive ovarian carcinoma in 1 (0.9\%).

Conclusion* Currently, RRSO is the only tool to reduce the risk of ovarian cancer in BRCA mutations carriers. However, the incidence of STIC after RRSO is not very high.

\section{NEGATIVE PREDICTIVE VALUE OF PAP SMEAR IN PATIENTS WITH LEUKOPLAKIA PATTERNS ON COLPOSCOPY}

1,1] Milojevic*, '2V Krsic, ${ }^{2}$ B Jocic Pivac. 'General Hospital Lazarevac, obgyn, Belgrade, Serbia; ${ }^{2}$ GAK Narodni front, obgyn, Belgrade, Serbia

\subsection{6/ijgc-2021-ESGO.547}

Introduction/Background*

The incidence rate for cervical cancer in Serbia is twice as high as in western European countries. In our daily practice we use cervical cytology and colposcopy as a routine screening method for cervical dysplasia and cervical cancer. HVP screening is not cover by insurance and large number of poorly complaint patients limited our resources and we warrant cervical biopsy in patients with leukoplakia on colposcopy examination regardless of the Pap smear results.

Methodology This was retrospective study evaluating 398 patients with leukoplakia abnormality on colposcopy who underwent cervical biopsy between January 2010 till January 2020 in General hospital Lazarevac, obgyn department.

We correlated results of conventional cervical cytology with results of biopsy to calculate predictive value of cervical cytology in excluding the diagnosis as cervical dysplasia and cervical cancer.

Result(s)* Biopsy results showed 92 patients with LGSIL, 35 with HGSIL, and 1 with invasive carcinoma of cervix. Normal finding on biopsy had 270 patients.

Normal Pap smear had 350 patients and 48 patients had some of cervical abnormality. Negative predictive value (NPV) of Pap smear for excluding severity dysplasia and cervical cancer was $97,39 \%$.

NPV for excluding any type of dysplasia in patients with leukoplakia was $74,86 \%$. Positive predictive value (PPV) of abnormal cytology was $86,79 \%$ for discover abnormal findings on cervical biopsy.

Conclusion* Pap smear is useful tool to guide necessity for cervical biopsy in patients with leukoplakia pattern on colposcopy. High negative predictive value in our study show us that cervical biopsy can be avoided in patients with leukoplakia and normal Pap smear.

\section{PATIENTS WITH CHEK2 MUTATION FOLLOWED UP IN A HEREDITARY GYNAECOLOGICAL CANCER UNIT}

${ }^{1} \mathrm{~A}$ Veiga-Fernández*${ }^{*},{ }^{1} \mathrm{M}$ Bernal Claverol, ${ }^{1} \mathrm{M}$ Ruiz Minaya, ${ }^{1} \mathrm{I}$ Aracil Moreno, ${ }^{1} \mathrm{C}$ Galvis Isaza, ${ }^{1} \mathrm{M}$ Díaz Perdigón, ${ }^{1} \mathrm{~A}$ Bretón Santos, ${ }^{1} \mathrm{M}$ Leñero Cirujano, ${ }^{1} \mathrm{P}$ Rincon Olbes, 'E Mendizábal Vicente, ${ }^{2}$ Echavarria Díaz-Guardamino, 'S Lizarraga Bonelli. 'Gregorio Marañón University General Hospital, Obstetrics and Gynaecology, Madrid, Spain; ${ }^{2}$ Gregorio Marañón University General Hospital, Medical Oncology, Madrid, Spain

\subsection{6/ijgc-2021-ESG0.548}

Introduction/Background* CHEK2 gene is located on chromosome 22 and participates in the maintenance of the genome and control of the cell cycle and apoptosis. Mutations in this gene are considered to increase the risk of breast cancer. An accumulated risk throughout life is estimated at $28-37 \%$ in these patients.

Methodology

Retrospective observational study Review of patients followed in the inherited cancer unit in a single tertiary centre between $1^{\text {st }}$ January 2012 until $28^{\text {th }}$ February 2021.

The statistical analysis was carried out using SPSS 22.0.

Result(s)* During the indicated period, we followed 401 patients with confirmed genetic mutations that predispose to developing gynaecological cancer. Of the total, 2.49\% (10/ 401) were carriers of a CHEK2 mutation.

Within the cohort of patients carrying a CHEK2 mutation, $7 / 10(70 \%)$ had a family history of breast cancer and $1 / 10(10 \%)$ a gastric cancer. $6 / 10$ patients were diagnosed with breast cancer at 23,37,37,38, 44 and 52 years old. One of them had a second contralateral breast cancer at age 47.

The histology of the breast cancer was either ductal carcinoma in situ or invasive ductal carcinoma. Tumor stage was 0 in one case, I in one case, IIA in two cases and IIIA in two cases. Surgery treatment was: unilateral mastectomy with homolateral axillary lymphadenectomy in 3 patients, conservative surgery in 1 patient, conservative surgery with selective sentinel lymph node biopsy in 1 patient and conservative surgery with homolateral axillary lymphadenectomy in 1 patient. Adjuvant treatment was: chemotherapy and hormone therapy in one case, radiation therapy and chemotherapy in one case, radiation therapy and hormone therapy in one case and radiation therapy, chemotherapy and hormone therapy in the other two.

Characteristics of these patients are summarized in table 1. Discussion There are several recommendations in the literature regarding the follow-up of patients carrying a CHEK2 mutation.

In general, it is recommended that all female carriers should be offered intensified surveillance programs for breast cancer including annual breast radiological testing.

Conclusion* Patients carrying CHEK2 mutations have a moderate risk of developing breast cancer and should be followed in specialized hereditary cancer units. 


\begin{tabular}{|c|c|c|c|}
\hline & CHEK2 Mutation $(n=10)$ & & Frequency(\%) \\
\hline & \multirow{3}{*}{ Family history of cancer } & No cancer & $2 / 10(20 \%)$ \\
\hline & & First degree & $6 / 10(60 \%)$ \\
\hline & & Second degree & $2 / 10(20 \%)$ \\
\hline & \multirow{3}{*}{$\begin{array}{l}\text { Personal history of cancer } \\
\text { (First tumour location) }\end{array}$} & No cancer & $3 / 10(30 \%)$ \\
\hline & & \begin{tabular}{|l|} 
Breast \\
\end{tabular} & $6 / 10(60 \%)$ \\
\hline & & Stomach & $1 / 10(10 \%)$ \\
\hline & \multirow[b]{2}{*}{$\begin{array}{l}\text { Histology of the primary breast } \\
\text { cancer }\end{array}$} & Ductal carcinoma in situ & $1 / 6(16.66 \%)$ \\
\hline & & $\begin{array}{l}\text { Invasive ductal } \\
\text { carcinoma }\end{array}$ & $5 / 6(83.33 \%)$ \\
\hline & \multirow{4}{*}{ Breast cancer stage } & Stage 0 & $1 / 6(16.66 \%)$ \\
\hline & & \begin{tabular}{|l|} 
Stage I \\
\end{tabular} & $1 / 6(16.66 \%)$ \\
\hline & & \begin{tabular}{|l|} 
Stage IIA \\
\end{tabular} & $2 / 6(33.33 \%)$ \\
\hline & & Stage IIIA & $2 / 6(33.33 \%)$ \\
\hline & \multirow{4}{*}{$\begin{array}{l}\text { Primary } \\
\text { treatment }\end{array}$} & $\begin{array}{l}\text { Unilateral mastectomy } \\
\text { with homolateral } \\
\text { axillary } \\
\text { lymphadenectomy }\end{array}$ & $3 / 6(50 \%)$ \\
\hline & & Conservative surgery & $1 / 6(16.66 \%)$ \\
\hline & & $\begin{array}{l}\text { Conservative surgery } \\
\text { with selective sentinel } \\
\text { lymph node biopsy }\end{array}$ & $1 / 6(16.66 \%)$ \\
\hline & & $\begin{array}{l}\text { Conservative surgery } \\
\text { with homolateral } \\
\text { axillary } \\
\text { lymphadenectomy }\end{array}$ & $1 / 6(16.66 \%)$ \\
\hline & \multirow[b]{5}{*}{ Adjuvant treatment } & Not needed & $1 / 6(16.66 \%)$ \\
\hline & & $\begin{array}{l}\begin{array}{l}\text { Chemotherapy } \\
\text { hormone therapy }\end{array} \\
\end{array}$ & $1 / 6(16.66 \%)$ \\
\hline & & $\begin{array}{l}\text { Radiation therapy and } \\
\text { chemotherapy }\end{array}$ & $1 / 6(16.66 \%)$ \\
\hline & & $\begin{array}{l}\text { Radiation therapy and } \\
\text { hormone therapy }\end{array}$ & $1 / 6(16.66 \%)$ \\
\hline & & $\begin{array}{l}\text { Radiation therapy, } \\
\text { chemotherapy and } \\
\text { hormone therapy }\end{array}$ & $2 / 6(33.33 \%)$ \\
\hline
\end{tabular}

\section{COMPARISON AND CORRELATION OF COLPOSCOPY INDICES WITH HISTOPATHOLOGY IN SCREEN POSITIVE PATIENTS}

${ }^{1}$ AG Nath*, ${ }^{1}$ PN Rema, ${ }^{2} \mathrm{R}$ Wesley, ${ }^{1} \mathrm{~S}$ Sambasivan, ${ }^{3} \mathrm{~S}$ J. ${ }^{1} R C C$, Gynaecological Oncology, Trivandrum, India; ${ }^{2} R C C$, Community Oncology, Trivandrum, India; ${ }^{3} R C C$, Surgical Oncology, Trivandrum, India

\subsection{6/ijgc-2021-ESG0.549}

Introduction/Background* Colposcopy was introduced to aid cervical biopsy to detect premalignant lesions of cervix. Reid, Swede and modified IFCPC nomenclature (2011) were later introduced to avoid subjective variation.

Methodology To study correlation between colposcopy scores like Reid score, Swede score and 2011 IFCPC nomenclature with histopathology in screening positive patients .

Prospective study of patients who underwent colposcopy for cervical cancer screening from June 2018 to January 2021. Reid score, Swede score and 2011 IFCPC nomenclature were documented in colposcopy charts. Colposcopy scorings and histopathology was statistically assessed using spearman's rank correlation test.

Result(s)* Out of total 220 females screened average age was 49.75. Reid score $>4$ correlated with $62.3 \%$ of high grade histopathology $(\mathrm{p}=0.149)$, Swede score $>5$ correlated with $61.3 \%$ of high grade histopathology report $(\mathrm{p}=0.038)$, while 2011 IFCPC nomenclature as major lesion correlated with $78.3 \%$ of high grade histopathology $(\mathrm{p}=0.001)$. Reid score has sensitivity $62.3 \%$, specificity $47.4 \%$; Swede score has sensitivity $61.3 \%$, specificity $52.6 \%$ with histopathology. IFCPC nomenclature had sensitivity $78.3 \%$, specificity $47.4 \%$ with histopathology. Measurement of agreement kappa was 0.096 for Reid score, 0.139 for Swede score and 0.254 for IFCPC nomenclature. $\mathrm{P}$ value was significant with IFCPC nomenclature, 0.001 .

Conclusion* 2011 IFCPC nomenclature has better correlation and more sensitivity in detecting high grade lesion while swede score is more specific in detecting high grade lesion. 